\title{
Aproximación al perfil sociodemográfico y comportamiento del asistente a rallies
}

\section{Approach to the sociodemographic profile and behavior of rally spectators}

\author{
Cristina Rico Bouza iD, Universidad de Vigo, España \\ cristina.rico.bouza@gmail.com
}

Noelia Araújo Vila iD, Universidad de Vigo, España

naraujo@uvigo.es

Jose Antonio Fraiz Brea iD, Universidad de Vigo, España

jafraiz@uvigo.es

\section{RESUMEN}

Los deportes de motor se constituyen como una de las modalidades deportivas con mayor número de adeptos. Los eventos automovilísticos en Galicia son reconocidos a nivel estatal por su excelente calidad, con un alto número de asistentes. Los rallies se establecen como la modalidad con mayor número de espectadores, lo que convierte a estas pruebas en un importante elemento dinamizador y desestacionalizador, celebrándose a lo largo de todo el año. El presente trabajo parte de la relevancia de estos eventos y pretende realizar una aproximación al perfil sociodemográfico y comportamiento turístico de los asistentes a rallies en Galicia. Para ello se recogen un total de 504 encuestas a asistentes a dichos eventos en el noroeste de España, concluyéndose que la mayoría de la población de estudio (alrededor del $44 \%$ ) tiene un alto grado de fidelidad en cuanto a la asistencia a las pruebas automovilísticas (rallies de asfalto en particular).

Palabras clave: turismo deportivo; eventos deportivos; automovilismo; rally.

\section{ABSTRACT}

Motor sports constitute one of the sporting categories with the largest number of fans. Motor racing events in Galicia are renowned for their excellent quality on a state level, with a high number of spectators. Rallies are the type of racing with the highest number of spectators, which helps to deseasonalize and boost tourism due to their distribution throughout the year. This study is based on the relevance of these events and seeks to determine the 
sociodemographic profile and tourist behavior of those attending rallies in Galicia. To do this, a total of 504 surveys were conducted with spectators of said events in the northwest of Spain. It may be concluded that the majority of the study population (around $44 \%$ ) exhibits a high degree of fidelity in terms of attendance to automobile races (asphalt rallies in particular).

Keywords: sport tourism; sport events; motorsport; rally.

\section{INTRODUCCIÓN}

El cambio de hábitos en la sociedad y, sobre todo, la diversificación en las motivaciones para viajar, han provocado la aparición de nuevas modalidades de turismo en los últimos años. Es el caso del turismo deportivo, un concepto relativamente reciente en la investigación académica (Gibson, 2006), aunque no tanto en su práctica, puesto que eventos deportivos como los Juegos Olímpicos llevan cientos de años movilizando a un gran número de personas para su disfrute.

En una aproximación a los últimos datos sobre esta forma de practicar turismo, y según el último informe publicado por el Instituto Nacional de Estadística (INE) (INE, 2019) se revela que el deporte se sitúa como una de las principales motivaciones de viaje por parte de los españoles. Por delante, solamente se sitúan otras formas clásicas como el turismo de sol y playa, el turismo cultural, el turismo de negocios y el turismo de naturaleza. Cabe destacar que el turismo motivado por el deporte se sitúa como una de las pocas modalidades de turismo que han crecido en el último período analizado (2015-2017) con un incremento del $8 \%$.

Nos encontramos, por lo tanto, ante una modalidad de turismo al alza que merece especial atención. Se entiende por turismo deportivo, aquellos "viajes basados en el ocio que llevan a las personas temporalmente fuera de sus comunidades de origen para participar en actividades físicas (turismo deportivo activo), ver actividades físicas (turismo deportivo de eventos) o venerar atracciones asociadas con actividades físicas (turismo deportivo de celebridades)" (Gibson, 2006, 17). En este estudio, la investigación se delimita a la modalidad turismo deportivo de eventos, en su variante deporte de motor.

Los deportes de motor incluyen las disciplinas automovilismo y motociclismo. Las pruebas de mayor prestigio a nivel mundial son: campeonato World Rally Championship (WRC), campeonato Fia Formula One Championship, Mundial de Moto GP, 24 horas de Le Mans o Dakar, entre otros.

El ámbito de análisis es la Comunidad Autónoma de Galicia. El motivo de esta elección se debe a la gran importancia que este deporte cobra en la región. Según la Federación Galega de Automobilismo (FGA) el número de pruebas celebradas en la comunidad es elevado, 12 en total en el año 2019 ( 2 más que en 2018 y 2017) (FGA, 2019a), lo que convierte a Galicia en una de las regiones con mayor número de carreras en esta disciplina a nivel nacional; $y$ corroboran la relevancia de esta modalidad los datos facilitados por la FGA, quienes cifran 
el número de espectadores en el cómputo de todas las pruebas del campeonato gallego de rallies en 800.000 personas (FGA, 2019b). Además, presentan una media de 30.000 asistentes por carrera sin tener en cuenta equipos participantes- (FGA, 2019b).

El objetivo del presente trabajo es conocer el comportamiento de los asistentes a rallies de asfalto (rally disputado en vías asfaltadas, en carreteras que son utilizadas de manera cotidiana y frecuente). Para ello se realiza en primer lugar una revisión teórica de los términos turismo deportivo, eventos deportivos y turismo automovilístico. A continuación, se matizan los objetivos del estudio y metodología utilizada en la parte empírica, optando por el uso de la técnica cuantitativa del cuestionario $(n=504)$, a través de la cual se analizará el comportamiento de los asistentes a rallies de asfalto dentro de la Comunidad Autónoma de Galicia. Por último, se exponen los principales resultados, discusión y conclusiones del trabajo.

\section{REVISIÓN TEÓRICA}

\subsection{Turismo deportivo. Contextualización y clasificación}

Siguiendo a Sánchez, Barajas y Alén (2013), deporte y turismo son conceptos que a pesar de que siempre han estado unidos, se han estudiado por separado. Los autores afirman que ambos son actividades con orígenes similares y practicadas ya desde la prehistoria, cuando los seres humanos realizaban desplazamientos fuera de su entorno habitual conjuntamente con actividades de desarrollo físico; practicando por lo tanto, deporte y turismo.

De acuerdo con la revisión bibliográfica de Weed (2009), son seis las primeras investigaciones y publicaciones sobre turismo deportivo más destacadas entre 1960 y 1990 . Mejía (1966) es el pionero con la primera publicación sobre este tema, ofreciendo algunos comentarios sobre el papel del deporte en las vacaciones. En la década de 1970 son Williams y Zelinksy (1970) y Baker y Gordon (1976) los que abordan este tema. Los primeros enfatizan el potencial generador de turismo de los mega-eventos como los Juegos Olímpicos, y los segundos analizan los deportes de invierno como importante nicho de mercado para el turismo. La década de 1980 es la más prolífera. Varios estudios hacen hincapié en el efecto económico de determinados eventos deportivos en el turismo (Armstrong, 1986; Kolsun, 1988; Lazer, 1986; Livesey, 1990; Ritchie, 1984); y otros sobre el deporte y el turismo como métodos regeneradores de las economías en declive (Beioley, Crookston y Tyer, 1988); Mcdowell, Leslie y Callicot, 1988). A pesar de ser un tema objeto de estudio académico, en la actualidad todavía no existe un consenso absoluto en cuanto a ciertos aspectos vinculados al mismo, como son la clasificación o tipos de turismo deportivo (Higham, 2018).

Con el fin de profundizar en la clasificación del turismo deportivo, se presenta en la Tabla 1 una revisión de la conceptualización de esta modalidad de turismo. Para ello se realizó una búsqueda en la base de datos Scopus a través de las palabras clave turismo deportivo. 


\section{Tabla 1. Conceptualización del turismo deportivo}

\begin{tabular}{|c|c|}
\hline Hall (1992) & $\begin{array}{l}\text { Son aquellos desplazamientos motivados por razones recreativas (no comer- } \\
\text { ciales), que se realizan fuera del lugar de residencia habitual y con el fin de } \\
\text { participar u observar actividades deportivas. }\end{array}$ \\
\hline Secall (1991) & $\begin{array}{l}\text { Se trata de aquella actividad de carácter turístico de la que forma parte algún } \\
\text { tipo de práctica deportiva, ya sea como objetivo fundamental o como objetivo } \\
\text { complementario. }\end{array}$ \\
\hline $\begin{array}{l}\text { Gammon y Robinson } \\
(1997,13)\end{array}$ & $\begin{array}{l}\text { "Individuos o grupos que participan activa o pasivamente en deportes com- } \\
\text { petitivos o recreativos durante los viajes que realizan fuera de su residencia } \\
\text { habitual". De esta definición, los autores derivan otras dos: } \\
\text { - Definición fuerte: participación activa o pasiva en eventos deportivos com- } \\
\text { petitivos. } \\
\text { - Definición débil: participación activa o pasiva en deportes recreativos. }\end{array}$ \\
\hline $\begin{array}{l}\text { Standeven y Knop (1999, } \\
12)\end{array}$ & $\begin{array}{l}\text { "Todas las formas activas o pasivas de la actividad deportiva, participando ca- } \\
\text { sualmente o de forma organizada, bien sea por razones comerciales o de nego- } \\
\text { cios o no, pero que necesariamente implique un viaje fuera del lugar habitual } \\
\text { de residencia o trabajo" }\end{array}$ \\
\hline $\begin{array}{l}\text { Ritchie y Adair (2004, } \\
\text { 158) }\end{array}$ & $\begin{array}{l}\text { "El turismo deportivo incluye viajar para participar en unas vacaciones deport- } \\
\text { ivas pasivas (por ejemplo, eventos deportivos y museos deportivos) o unas } \\
\text { vacaciones deportivas activas (por ejemplo, buceo, ciclismo, golf), y puede in- } \\
\text { cluir casos en los que el deporte o el turismo sean la actividad dominante o la } \\
\text { razón para viajar" }\end{array}$ \\
\hline Pigeassou $(2004,287)$ & $\begin{array}{l}\text { "Un experimento humano que se centra en un conjunto de servicios necesa- } \\
\text { rios para la realización de los desplazamientos temporales no profesionales } \\
\text { hacia destinos específicos para experimentar la cultura deportiva" }\end{array}$ \\
\hline $\begin{array}{l}\text { Latiesa y Paniza, (2006, } \\
\text { 136) }\end{array}$ & $\begin{array}{l}\text { "Aquellas actividades que se desarrollan en un lugar distinto de la residencia } \\
\text { habitual y que tienen como objetivo principal la recreación turística y como } \\
\text { actividad complementaria vacacional la práctica deportiva" }\end{array}$ \\
\hline Gibson $(2006,17)$ & $\begin{array}{l}\text { "Viajes basados en el ocio que llevan a las personas temporalmente fuera de } \\
\text { sus comunidades de origen para participar en actividades físicas (turismo de- } \\
\text { portivo activo), ver actividades físicas (turismo deportivo de eventos) o vener- } \\
\text { ar atracciones asociadas con actividades físicas (turismo deportivo de celebri- } \\
\text { dades)" }\end{array}$ \\
\hline $\begin{array}{l}\text { González Molina (2008, } \\
86)\end{array}$ & $\begin{array}{l}\text { "Aquel tipo de turismo cuya motivación principal la constituye la realización } \\
\text { de un conjunto de prácticas físico-deportivas, es decir aquellas modalidades } \\
\text { deportivas con unas características muy definidas por su reglamentación, su } \\
\text { institucionalización, su depurada técnica, y por el tipo de instalaciones, materi- } \\
\text { ales, artilugios e implementos que necesitan para su práctica, mejorar su nivel } \\
\text { de calidad de vida a través de su salud corporal, física y psicológica, mejorar } \\
\text { sus autoestima personal, su autorrealización, su proyección social, el carácter } \\
\text { lúdico, hedonístico y recreativo de todas las actividades posibles, la búsqueda } \\
\text { de nuevos retos y superaciones personales, etc." }\end{array}$ \\
\hline $\begin{array}{c}\text { Hinch e Ito (2018) y Kiani } \\
\text { et al. (2019) }\end{array}$ & Introducen la variable de la sostenibilidad en la práctica del turismo deportivo. \\
\hline Perić et al. (2019) & $\begin{array}{l}\text { Proponen modelos de negocio para diferentes experiencias de turismo deport- } \\
\text { ivo al aire libre, basándose en los conocimientos de los participantes de even- } \\
\text { tos deportivos activos y los organizadores de eventos deportivos. }\end{array}$ \\
\hline
\end{tabular}

Fuente: Elaboración propia a partir de los autores citados en la tabla. 
Del análisis de las definiciones anteriores, se extrae que aparentemente existe un consenso en cuanto a qué es el turismo deportivo. Autores como Latiesa y Paniza (2006) y González Molina (2008) consideran turismo deportivo solamente a aquellos viajes en los que se incluye la práctica de algún tipo de deporte. Sin embargo, la versión más extendida es aquella en la que los investigadores contemplan tanto la práctica activa de deporte como la pasiva (observación) de deporte. Es el caso de Hall (1992), Gammon y Robinson (1997), Standeven y Knop (1999) y Gibson (2006). Por otra parte, Standeven y Knop (1999) son los únicos que incluyen a los viajes de negocios dentro de su definición. El resto de autores, o bien no hacen referencia, o bien consideran turismo deportivo solo a aquellos que no se realizan por motivos comerciales.

Se ha decidido tomar como referencia las clasificaciones de los autores más relevantes en el estudio del turismo deportivo, las cuales se muestran a continuación en la Tabla 2, por orden cronológico.

Tabla 2. Clasificación del turismo deportivo

\begin{tabular}{|c|c|}
\hline $\begin{array}{l}\text { Kurtzman y Zauhar } \\
\text { (1997) }\end{array}$ & $\begin{array}{l}\text { - Attractions: se refiere a atracciones naturales (parques naturales o mon- } \\
\text { tañas) o construidas por el hombre (museos, parques temáticos deportivos). } \\
\text { - Resorts: complejos turísticos o villas con el deporte como enfoque principal } \\
\text { (estaciones de ski o instalaciones de entramiento deportivo). } \\
\text { - Cruises: cruceros que tienen el deporte como objetivo principal. } \\
\text { - Tours: en referencia a viajes relacionados con el deporte. } \\
\text { - Events: asistencia a eventos deportivos. }\end{array}$ \\
\hline $\begin{array}{c}\text { Gammon y Robinson } \\
\text { (1997) }\end{array}$ & $\begin{array}{l}\text { - Deporte Turístico: en este caso existen dos tipos. } \\
\text { - Definición fuerte: participación activa o pasiva en un evento deportivo } \\
\text { competitivo. Ejemplo: Juegos Olímpicos, partidos de Fútbol, Torneos in- } \\
\text { ternacionales... } \\
\text { - Definición débil: participación en un evento recreativo. Ejemplo: sender- } \\
\text { ismo, excursionismo, ski, piragüismo ... } \\
\text { - Turismo Deportivo: de nuevo existen dos tipos. } \\
\text { - Definición débil: visitantes que participan en alguna forma menor de de- } \\
\text { porte u ocio, siendo su participación meramente incidental. Ej.: bolos, } \\
\text { piscina, remo, bailar... } \\
\text { - Definición fuerte: turistas que como refuerzo secundario participan pasi- } \\
\text { va o activamente en un deporte. Ej.: cruceros deportivos, clubs de salud } \\
\text { y fitness ... }\end{array}$ \\
\hline Gibson (1998) & $\begin{array}{l}\text { - Active sport tourism: individuos que participan en actividades deportivas } \\
\text { mientras están de vacaciones. } \\
\text { - Event sport tourism: personas que acuden a un evento deportivo. } \\
\text { - Nostalgia sport tourism: personas que acuden a lugares relacionados con } \\
\text { grandes eventos deportivos o personajes (por ejemplo, museos) }\end{array}$ \\
\hline Standeven y Knop (1999) & $\begin{array}{l}\text { - Vacaciones: dentro de estas existe el deporte activo (vacaciones de ac- } \\
\text { tividades deportivas o actividades deportivas en vacaciones) y el deporte } \\
\text { pasivo (observador conocedor, eventos deportivos, museos, observador } \\
\text { casual...). }\end{array}$ \\
\hline
\end{tabular}

Fuente: Elaboración propia a partir de los autores citados en la tabla. 
Como se puede apreciar en la tabla, la disparidad de clasificaciones es significativa. En el caso del modelo de Gammon y Robinson (1997), donde no se ve, por ejemplo, representado en ningún lugar a aquellos turistas que acuden como espectadores a un evento, siendo este el motivo principal del viaje. Sin embargo, tanto esta clasificación como la de Standeven y Knop (1999) hacen referencia a la actitud que presenta el turista con respecto a la práctica deportiva, esto es, activa o pasiva. Otro apunte muy importante que introducen estos últimos autores en la clasificación del turismo deportivo son las razones comerciales o de negocios, hecho que constituye una evolución muy importante en el concepto (Jiménez Naranjo, 2015).

\subsection{Los eventos deportivos}

El turismo de eventos deportivos, definido por Delpy Neirotti $(2003,8)$ como "aquellas actividades o competiciones deportivas capaces de atraer un número considerable de visitantes con el objeto de participar o asistir como espectadores", constituye en la actualidad una gran oportunidad para los destinos que buscan aumentar sus atractivos, tanto por el número de turistas que atraen como por su impacto económico (Getz, 2003). Un factor clave a la hora de decidir a dónde viajar es la asistencia a eventos deportivos (Gibson, Qi, y Zhang, 2008; Latiesa y Paniza, 2006; Paramio-Salcines, Ruiz Barquín y Baena Arroyo, 2017; Standeven y Knop, 1999)

En los últimos años, este segmento del turismo deportivo ha atraído la atención de numerosos investigadores, centrándose sus estudios en áreas como: conceptualización y evolución del turismo de eventos deportivos (Getz, 2008), el impacto económico (Burgan y Mules, 1992; Daniels, Norman y Henry, 2004; Nyikana y Tichaawa, 2018; Peric, 2019; Yeh et al., 2018), el comportamiento del turista (Getz y McConnell, 2011; Gibson, Willming y Holdnak, 2003) o el impacto en la imagen del destino y la intencionalidad de volver (Chalip, Green y Hill, 2003; Kaplanidou y Vogt, 2007).

Los eventos turísticos pueden ser divididos en tres o cuatro grupos, según los principales autores. O’Connor (2012) aporta la clasificación más sencilla:

- Mega events (megaeventos): en virtud de su tamaño en términos de asistencia, mercados objetivo, nivel de participación pública, efectos políticos, cobertura televisiva, construcción de instalaciones e impacto en el tejido económico y social de las comunidades anfitrionas. Ejemplo: Juegos Olímpicos, FIFA World Cup, Gran Premio F1.

- Hallmark events (evento distintivo): eventos de una duración limitada, desarrollados primordialmente para mejorar el conocimiento, el atractivo y la rentabilidad de un destino turístico a corto plazo, a largo plazo o ambos. Confían su éxito en la singularidad, el estado o en la oportunidad para crear interés y atraer la atención. Se llevan a cabo repetidamente en el mismo destino, para que al mencionar el evento venga a la mente inmediatamente el lugar donde se realiza. Ejemplo: Festival de Cine de Cannes, Tour de Francia.

- Major events (eventos importantes): de menor escala que los anteriores, pero lo suficientemente grandes como para atraer la atención de los medios de comunicación nacionales, para atraer a un gran número de espectadores y proporcionar beneficios económicos. Ejemplo: Australia Open Tennis Championship. 
Getz (2008) contribuye con una visión más amplia, aportando dos versiones de clasificación de eventos turísticos, dependiendo del tamaño o de la temática. Por una parte, los clasifica en función del tamaño (mega eventos, eventos distintivos, eventos regionales y eventos locales) y por otra según la temática (cultural, política y nacional, artes y entretenimiento, negocios, ciencia y educación, deporte y evento privado).

Los eventos deportivos, a su vez, pueden también subdividirse, atendiendo a diferentes motivos. Son varios los estudios que proponen diferentes clasificaciones atendiendo a distintos factores (Getz, 2008; Gratton, Dobson y Shibi, 2000; O'Connor, 2012). A continuación, en la Tabla 3, se detalla el modelo propuesto por Barajas, Salgado y Sánchez (2012), una adaptación de otros autores, y uno de los modelos más completos que se ha encontrado.

Tabla 3. Clasificación de los eventos deportivos

\begin{tabular}{|c|c|c|}
\hline $\begin{array}{l}\text { Tipo de } \\
\text { eventos }\end{array}$ & Características generales & Características económicas \\
\hline Tipo A & $\begin{array}{l}\text { Irregulares, especiales y únicos } \\
\text { Mayor asistencia de competidores y de } \\
\text { espectadores internacionales Interés mediá- } \\
\text { tico }\end{array}$ & $\begin{array}{l}\text { Menor frecuencia de celebración } \\
\text { Gran competitividad entre los países y ciu- } \\
\text { dades para ganar su candidatura }\end{array}$ \\
\hline Tipo B & $\begin{array}{l}\text { Regular } \\
\text { Mayor asistencia de espectadores } \\
\text { Interés mediático }\end{array}$ & $\begin{array}{l}\text { Menor frecuencia de celebración } \\
\text { Dominantes en términos de desarrollo } \\
\text { económico } \\
\text { Poca competitividad entre los países y ciu- } \\
\text { dades para ganar su candidatura }\end{array}$ \\
\hline Tipo C1 & $\begin{array}{l}\text { Irregular o regulares que cambian de sede } \\
\text { Asistencia de espectadores y competidores } \\
\text { internacionales }\end{array}$ & $\begin{array}{l}\text { Mayor frecuencia de celebración } \\
\text { Actividad económica limitada } \\
\text { Inciertos en términos de impacto econó- } \\
\text { mico }\end{array}$ \\
\hline Tipo C2 & $\begin{array}{l}\text { Regulares } \\
\text { Asistencia de competidores y espectadores } \\
\text { Internacionales }\end{array}$ & $\begin{array}{l}\text { Mayor frecuencia de celebración } \\
\text { Actividad económica limitada } \\
\text { Inciertos en términos de impacto econó- } \\
\text { mico }\end{array}$ \\
\hline Tipo D1 & $\begin{array}{l}\text { Irregular o regulares que cambian de sede } \\
\text { No hay asistencia de espectadores } \\
\text { Internacionales }\end{array}$ & $\begin{array}{l}\text { Mayor frecuencia de celebración } \\
\text { Actividad económica limitada } \\
\text { Motivos de concesión fuera del ámbito } \\
\text { puramente económico }\end{array}$ \\
\hline Tipo D2 & $\begin{array}{l}\text { Regulares } \\
\text { No hay asistencia de espectadores } \\
\text { Internacionales }\end{array}$ & $\begin{array}{l}\text { Mayor frecuencia de celebración } \\
\text { Actividad económica limitada } \\
\text { Motivos de concesión fuera del ámbito } \\
\text { puramente económico }\end{array}$ \\
\hline Tipo E & $\begin{array}{l}\text { Regulares, irregulares o regulares con } \\
\text { cambio de sede } \\
\text { Menor asistencia de competidores y espec- } \\
\text { tadores } \\
\text { No genera interés en los medios de } \\
\text { Comunicación }\end{array}$ & $\begin{array}{l}\text { Mayor frecuencia de celebración } \\
\text { Actividad económica muy limitada } \\
\text { Motivos de concesión fuera del ámbito } \\
\text { puramente económico }\end{array}$ \\
\hline
\end{tabular}

Fuente: elaboración propia a partir de Barajas, Salgado y Sánchez (2012). 
Como se puede apreciar en la tabla, los eventos deportivos pueden clasificarse atendiendo a criterios como la regularidad en la celebración, el número de asistentes (competidores y espectadores), el interés mediático y el impacto económico generado. Esta última cuestión es, quizá, el elemento encontrado con más frecuencia en la literatura sobre turismo (Barajas, Salgado y Sánchez, 2012), un dato que revela que esta clase de eventos resultan un elemento de gran relevancia para las comunidades locales, además de favorecer a la dinamización turística de los destinos (Barajas, Salgado y Sánchez, 2012).

\subsection{Turismo automovilístico y de rallies}

Como se avanzaba en el punto anterior, el turismo de eventos deportivos se ha convertido en una sub-industria vital para muchas comunidades (Del Chiappa, Tinaz, y Turco, 2014) y en este escenario, los eventos automovilísticos se han considerado durante mucho tiempo como un vehículo para el desarrollo del turismo deportivo que debe ser aprovechado para el bien económico y social de las áreas anfitrionas (Chalip, 2004; O’Brien, 2007).

Para comprender las dimensiones del automovilismo, es preciso poner el término en contexto. Los deportes de motor ${ }^{1}$, como su nombre indica, son aquellas disciplinas en las que el medio de competición es un vehículo motorizado. Henry, Angus, Jenkins y Aylett $(2007,1)$, los definen, en términos generales, como una "carrera competitiva realizada por máquinas equivalentes, en pistas y circuitos designados. Estas máquinas incluyen, por ejemplo, motocicletas, motocross, karts, autos históricos, [...], rallies, vehículos deportivos compactos, [...] y Fórmula Uno".

Los deportes de motor están compuestos por cuatro disciplinas: automovilismo, motociclismo, motonáutica y aeronáutica. Cada una de las disciplinas se puede subdividir en diferentes categorías, variando estas en función del país en las que se practiquen. En el caso del automovilismo, se tomará como referencia la clasificación ofrecida por Henry et al. (2007), por tratarse de la británica, cuna del automovilismo mundial (Hassan y O'Connor, 2009). Se profundizará en la española más adelante.

- Autocross: circuito en hierba. Los coches compiten individualmente contra reloj.

- Autotest: los coches compiten solos, contra el reloj. El conductor debe negociar una ruta establecida entre los obstáculos, usualmente torres de plástico o conos. La superficie es normalmente lisa, a menudo asfaltada.

- Car racing (carreras de coches): los coches compiten entre sí en circuitos de asfalto especialmente diseñados para ese fin.

- Drag racing (carreras de aceleración): se trata de carreras de resistencia. Su objetivo es cubrir una determinada distancia en el menor tiempo posible.

- Hillclimb and sprint (subidas): dos ramas similares del automovilismo. Cada evento tiene lugar en una superficie lisa y sellada a lo largo de una distancia medida contrareloj.

1. También conocidos como motorsport, su traducción al inglés, un término muy extendido en el argot del sector en España. 
- Karting: similar a las carreras de coches en que los competidores compiten entre sí en circuitos de asfalto. Los karts, sin embargo, son más pequeños y más básicos en apariencia que los coches de carreras.

- Off road (todoterreno): se llevan a cabo en terrenos difíciles y requieren vehículos especializados, normalmente con tracción en las cuatro ruedas.

- Rallycross: se lleva a cabo en lugares permanentes, utilizando una mezcla de secciones de superficie en asfalto y fuera de la carretera (tierra). Los coches compiten contrareloj en las eliminatorias de calificación, y luego entre sí en las finales.

- Rallying (rallies): se trata de dos personas que trabajan juntas: un conductor y un copiloto. Los coches normalmente salen en intervalos de un minuto, compitiendo contrareloj en lugar de directamente entre sí.

- Trials: el elemento competitivo es la capacidad de subir pendientes de dificultad variable. Cada ensayo tiene varias secciones observadas en terreno privado.

- Rallies de asfalto: rally disputado en vías asfaltadas, en carreteras que son utilizadas de manera cotidiana y frecuente.

Las disciplinas automovilísticas están generalmente regladas por una Federación, siendo la Federación Internacional de Automovilismo (FIA) el máximo exponente regulador a nivel mundial. Cabe resaltar que no todas las disciplinas que se relatan en la clasificación de Henry et al. (2007) están recogidas dentro de dichos campeonatos, ya que no todas cuentan con la misma relevancia y seguimiento a nivel internacional. En total, el organismo se encarga de la organización de más de 1.000 competiciones automovilísticas: 305 pruebas pertenecientes a sus propios campeonatos y copas, y las restantes a otras carreras de carácter internacional (FIA, 2018).

Los campeonatos más conocidos a nivel mundial de los organizados por la FIA son la Fórmula 1 (con sus variantes Fórmula E, Fórmula 2, Fórmula 3,...) y el WRC (World Rally Championship-Campeonato Mundial de Rallies). El organismo se encarga de la organización de 34 campeonatos en las disciplinas de: circuítos, rallies, subidas, off-road, cross country rallies, energías alternativas, carreras de aceleración y karting (FIA, 2019).

Los rallies están regulados por 11 campeonatos, siendo el WRC el más relevante y conocido a nivel mundial, como se detalla en el párrafo anterior. Sus orígenes datan de 1973 y está considerado como uno de los campeonatos de automovilismo más duros del mundo FIA (2019).

Esta modaldiad posee las mismas características en prácticamente todo el mundo, por lo que se tomará como referencia la aportada por WRC (2019a), donde se especifica que cada rally se divide en un número de secciones cronometradas, popularmente conocidas como tramos, disputadas en carreteras cerradas al tráfico. Generalmente, el rally se divide en varios días, siendo los primeros (1 o 2 días) jornadas de reconocimiento, donde los pilotos pueden dar pasadas especiales para hacer sus notas. En los siguientes días ( 102 , dependiendo de la prueba) se celebra la competición en sí, donde los coches salen uno detrás de otro, separados por un intervalo de tiempo, para intentar completar los tramos en el menor tiempo posible. Además de automóviles, en algunos rallies pueden participar camionetas, camiones y motocicletas. Un rally se desarrolla en una carretera o en un terreno abierto, con una ruta preestablecida por la 
organización de la carrera. Una vez que se completan todas las etapas, se suman los tiempos: el ganador del rally será aquel competidor que haya sumado menor tiempo y que, por lo tanto, haya sido el más rápido en recorrer los distintos trayectos de la competencia.

Regresando al Campeonato Mundial de Rallies (WRC), el calendario se reparte a lo largo de todo el año por América, Europa y Oceanía en un total de 14 carreras (WRC, 2019a), atrayendo hasta 11 millones espectadores "en vivo" y más de 817 millones de audiencia de 180 países diferentes (Mackellar y Reis, 2014; Hassan y O'Connor, 2009; WRC, 2019b). Se puede conocer al interesado en estos a través de los seguidores de los canales online y medios sociales de WRC.

En el ámbito turístico, los estudios que se han podido encontrar son de carácter aislado y versan principalmente sobre el impacto económico generado por esta clase de eventos, el comportamiento del espectador en general o sobre la imagen del destino que proyectan a los seguidores. Se detallan a continuación: WRC Irlanda 2007 (O'Connor, 2010; Hassan y McCulloch, 2007), WRC Australia 2009 y 2011 (Mackellar, 2013; Mackellar y Reis, 2014), WRC RACC Cataluya-Costa Daurada 2008 (RACC, 2009), WRC Finlandia 2011-2013 (Rasku y Turco, 2017) y WRC Rally de Portugal 2016 (ACP, 2016). Destaca también el estudio de Hassan y O'Connor (2009), quienes realizan una aproximación al perfil del asistente de 6 pruebas del campeonato del año 2007.

LA WRC destaca la importancia del rally para la economía, que generó en la pasada edición de 2018 un gasto directo de 72,9 millones de euros (casi 2 millones más que la edición anterior, batiendo un nuevo récord); impacto que ningún otro evento deportivo o turístico ha conseguido generar en la historia del país. Se estimó que asistieron a la prueba alrededor de un millón de aficionados. Los datos arrojaron también elevados índices de satisfacción (8 sobre 10) y una intencionalidad de más del $90 \%$ en volver a visitar la zona en los próximos 3 años.

\subsubsection{Los rallies de asfalto}

Aunque en el epígrafe anterior se adelanta la definición de rally de asfalto, creemos necesario profundizar un poco más en este tipo de producto por ser en el que se centra la parte empírica de este trabajo. Se entiende por éste aquel rally que se lleva a cabo en vías asfaltadas que se usan habitualmente por vehículos. Ejemplo de ello muy representativo es el Rally de Montecarlo, donde se disputan algunos tramos sobre nieve y otros sobre asfalto; los segundos pertenecerían a esta categoría.

La Real Federación Española de Automovilismo (RFEDA) realiza una división de pruebas automovilísticas en dos modalidades principales: carretera y circuitos. Los rallyes de asfalto pertenecen a la modalidad de carretera, que engloba las siguientes categorías: asfalto-tierra, asfalto, tierra, todo terreno, vehículos históricos y energías alternativas (RFEDA, Real Federación Española de Automovilismo, 2019).

El calendario de los rallyes de asfalto se distribuyó en 2019 en 11 pruebas a lo largo del territorio nacional (RFEDA, 2019), coincidiendo 3 de ellas en el territorio gallego. Por otra parte, en la literatura académica, y al igual que ocurre con este deporte en general, el estudio de la repercusión de esta clase de eventos es relativamente reducido. 


\section{MUESTRA Y METODOLOGÍA}

Tras elaborar el marco teórico de este trabajo, el objetivo de la parte empírica de esta investigación se centra en conocer el comportamiento de los asistentes a rallies de asfalto en Galicia en el año 2018, comunidad notoria en este tipo de eventos. La relevancia del automovilismo en Galicia viene dada en la antigüedad del Campeonato Gallego de Rallies, uno de los más veteranos en el panorama nacional (data de 1979, según FGA, 2019b). Además, otro dato en cuanto a la magnitud es el número de pruebas o el número de inscritos en cada carrera, ya que el CGR posee el calendario con mayor número de pruebas de toda España y es, sin duda, el que mayor número de inscritos de media presenta en todo el país, unos 140 por prueba (FGA, 2019b).

Los objetivos específicos son los que siguen a continuación:

- Determinar el perfil sociodemográfico de los asistentes a rallies en Galicia en el año 2018, así como la motivación que les lleva a consumir este tipo de turismo.

- Elaborar una estimación del gasto turístico que realizan cada vez que se desplazan para acudir a un rally.

- Hallar los intereses generales y tipos de productos turísticos que demandan los individuos objeto del estudio, así como el potencial de consumo turístico.

Para alcanzar los objetivos anteriores, se ha optado por la herramienta de recogida de datos primarios de la encuesta. Según Malhotra $(2004,168)$, una encuesta "incluye un cuestionario estructurado que se da a los encuestados y que está diseñado para obtener información específica".

En el caso del presente trabajo, la encuesta y su estructura han sido diseñadas de tal forma que responda a los objetivos específicos planteados anteriormente. Previa a la recogida de datos, se ha realizado un pretest a investigadores de la Universidad de Vigo, comprobando así la correcta redacción de las preguntas y respuestas propuestas. En total, han sido 30 las preguntas propuestas, divididas en 3 bloques:

- Bloque I (preguntas 1 a 15): perfil sociodemográfico de la muestra. Preguntas habituales de perfil con varias opciones de respuesta: género, edad, nivel de estudios y ocupación. Tres preguntas abiertas, país de residencia, localidad de residencia y número de pruebas en las que compite (si es el caso). Tres preguntas multirrespuesta sobre el motivo por el que acude a rallies (aficionado, acompañante u otro); a cuántas pruebas asistió en 2018 del campeonato gallego (intervalos de 1 a3; 4 a 7; más de 7; todas o ninguna); a cuántas pruebas asistió en 2018 del campeonato nacional (1, 2, todas o ninguna). Y 5 preguntas de respuesta dicotómica (sí o no): si forma parte de algún equipo; si compite en algún rally en Galicia; si se desplaza fuera de su comunidad; si se desplaza fuera de España y si frecuenta otro tipo de pruebas de automovilismo.

- Bloque II (preguntas 16 a 21): gasto turístico realizado. En este bloque se realizan cuatro preguntas multirrespuesta: frecuencia con que se hospeda fuera de su residencia habitual (escala Likert de 1 a 5, siendo 1 nunca y 5 siempre); tipo de alojamiento usado (residencia habitual, casa de amigos, establecimiento hotelero, turismo rural u otro); duración de la estancia (intervalos de 1 a 2 días; 2 a 5; más de 5); gasto medio diario (menos de 10 euros; de 11 a 15; de 16 a 20 y más de 20); y gasto medio diario realizado 
(de 5 a 10; 11 a 15; 16 a 20; más de 20). Y una pregunta dicotómica (sí o no) sobre e luso de servicios complementarios como restaurantes.

- Bloque III (preguntas 22 a 30): actividades turísticas realizadas y potencial de consumo turístico futuro. Cinco preguntas multirrespuesta: realización de otras actividades turísticas (escala Líkert de 1 a 5 , siendo 1 nunca y 5 siempre); tipo de productos que consume (turismo activo, turismo cultural, turismo gastronómico, turismo termal, etc.); si no realiza actividades complementarias, ¿ivuelve a la zona para conocerla mejor? (escala Líkert de 1 a 5 , siendo 1 nunca y 5 siempre); qué productos despertarían mayor interés (visitas guiadas, gastronomía, turismo termal, etc.); qué turismo practicó (activo, cultural, gastronómico, etc.). Dos preguntas dicotómicas (sí o no): si estaría dispuesto a comprar un paquete de varios días de alojamiento más actividades y si practicó alguna clase de turismo. Y, por último, dos preguntas de respuesta abierta: cuánto pagaría por algún tipo de actividad turística y qué le motivaría a ampliar su estancia en el lugar donde se celebra un rally.

La población objeto del presente estudio son aquellos individuos que han acudido en el año 2018 a rallies de asfalto en Galicia. Por ese motivo, la técnica de muestreo escogida ha sido la no probabilística de bola de nieve, es decir, la selección de un grupo inicial de encuestados, a los cuales se les pide que identifiquen a otros que pertenecen a la población objeto, lo que conlleva al conocido efecto de bola de nieve (Malhotra, 2004). Este grupo inicial fue localizado a través del grupo de Facebook "Galicia Rally". Los datos obtenidos fueron analizados con el software SPSS Statistics. Los análisis realizados fueron descriptivos, correlaciones (coeficiente de correlación de Pearson) y análisis clúster (o conglomerados) el cual permite agrupar a individuos con características homogéneas y a la vez diferenciados del resto de grupos.

Mediante la técnica mencionada anteriormente, se han recogido en el período comprendido entre abril y junio de 2019, un total de 504 cuestionarios de modo online. En un primer momento se planificó un muestreo aleatorio, donde siendo la población finita (menos de 100.000 individuos) y considerando un error del $5 \%$ el tamaño muestral era igual a 380 encuestas. Dado que no existe un censo de asistentes a rallies donde poder estimar la aleatoriedad, se optó por la técnica no probabilística anteriormente mencionada (bola de nieve). En tal caso se intentó recoger un número de encuesta superior al anteriormente fijado.

\section{RESULTADOS}

\subsection{Perfil sociodemográfico}

Se ha determinado que el perfil sociodemográfico del asistente a rallies de asfalto en Galicia en la temporada 2018 se trataba mayoritariamente de un hombre (85\%), situado en un tramo de edad comprendido entre los 19 y los 44 años, con un nivel de estudios de Formación Profesional (básica, acceso sin ESO (Educación Secundaria Obligatoria); grado medio, acceso con ESO; o grado superior, acceso con Bachillerato) y trabajador por cuenta ajena o propia. El $74,6 \%$ de los encuestados residían en Galicia, resultando también elevado el porcentaje de asturianos que acuden a rallies en Galicia, un 11,5\%. El seguimiento de estas pruebas por parte de los habitantes de otras comunidades como Cantabria, Castilla-León y Andalucía también ha sido resaltable (Tabla 4). 
Tabla 4. Perfil sociodemográfico de la muestra

\begin{tabular}{|c|c|c|}
\hline & $N=504$ & $\%$ \\
\hline \multicolumn{3}{|l|}{ Género } \\
\hline Hombre & 432 & $85,7 \%$ \\
\hline Mujer & 72 & $14,3 \%$ \\
\hline \multicolumn{3}{|l|}{ Edad } \\
\hline Menos de 18 años & 8 & $1,6 \%$ \\
\hline 19 a 30 años & 270 & $53,6 \%$ \\
\hline 31 a 44 años & 195 & $38,7 \%$ \\
\hline 45 a 65 años & 31 & $6,2 \%$ \\
\hline \multicolumn{3}{|l|}{ Educación } \\
\hline Sin educación formal & 1 & ,2\% \\
\hline Primarial & 18 & $3,6 \%$ \\
\hline Secundaria & 71 & $14,1 \%$ \\
\hline Formación profesional & 289 & $57,3 \%$ \\
\hline Estudios universitarios & 98 & $19,4 \%$ \\
\hline Postgrado o Doctorado & 27 & $5,4 \%$ \\
\hline \multicolumn{3}{|l|}{ Ocupación } \\
\hline Empleado/autónomo & 400 & $79,4 \%$ \\
\hline Estudiante & 59 & $11,7 \%$ \\
\hline Desempleado & 42 & $8,3 \%$ \\
\hline Jubilado & 2 &, $4 \%$ \\
\hline No activo & 1 &, $2 \%$ \\
\hline \multicolumn{3}{|l|}{ País de residencia } \\
\hline España & 499 & $99 \%$ \\
\hline Otros* & 5 & $1 \%$ \\
\hline \multicolumn{3}{|l|}{$\begin{array}{l}\text { Provincia de residencia } \\
\text { (para españoles) }\end{array}$} \\
\hline A Coruña & 165 & $32,7 \%$ \\
\hline Pontevedra & 92 & $18,3 \%$ \\
\hline Ourense & 61 & $12,1 \%$ \\
\hline Asturias & 58 & $11,5 \%$ \\
\hline Lugo & 28 & $5,6 \%$ \\
\hline Cantabria & 19 & $3,8 \%$ \\
\hline Madrid & 10 & $2,0 \%$ \\
\hline Barcelona & 5 & $1,0 \%$ \\
\hline León & 5 & $1,0 \%$ \\
\hline Others & 61 & $12,1 \%$ \\
\hline
\end{tabular}

*Incluye Alemania, Israel, Italia, Malta and Países Bajos. 
En relación al motivo que les ha llevado a asistir a rallies en Galicia, el 100\% de las personas que respondieron a la encuesta manifiesta acudir a esta clase de pruebas por afición. En este porcentaje se analiza los que acuden a rallies por cualquier tipo de motivación menos la profesional. El acudir por motivos profesionales no se contempla ya que no se elige el destino, sino que es de obligada asistencia por ser parte de su trabajo. Entre los rallies más populares de Galicia en 2018 se encontraron el Rally de Noia (14,2\%), el de A coruña (8,5\%), Narón (7,5\%), Rías Baixas (6,6\%) y Ourense Ribeira Sacra $(5,7 \%)$.

El diagrama de cajas (Figura 1) muestra que el ser fan es la motivación que abarcaba el mayor rango de edad, desde menos de 18 a los 65 . Sin embargo, la media de los que acompañaban a amigos es de 31 a 44 años y los que trabajaban en algo vinculado al rally se sitúan entre los 19 y 30 años de media.

Figura 1. Diagrama de cajas motivación/edad

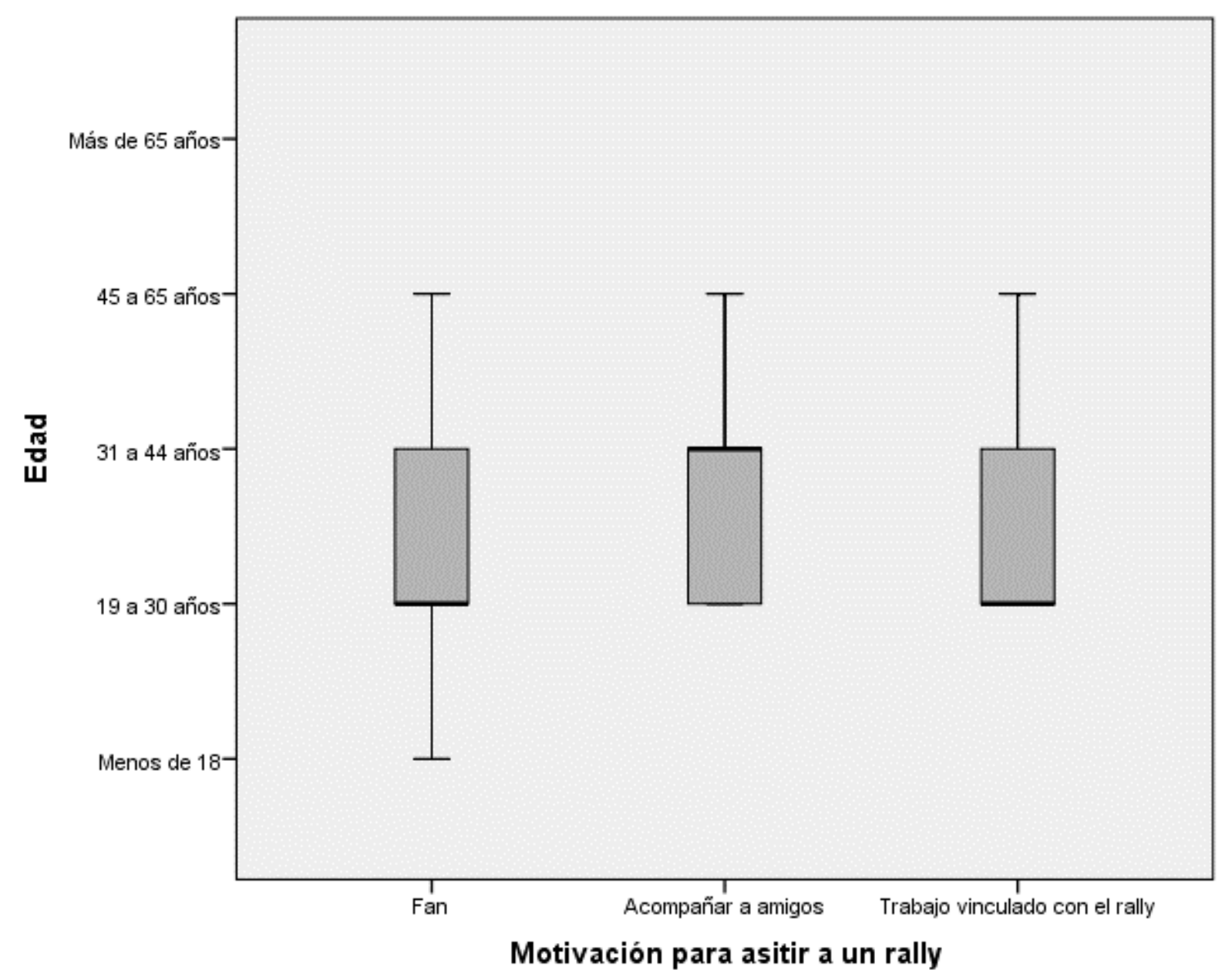


Con respecto a la forma en la que acudían, el $80,7 \%$ de los asistentes a rallies de asfalto han afirmado asistir a estos eventos en grupo, mientras que un $12,7 \%$ lo han hecho en pareja y solamente el $6,6 \%$ sin compañía alguna. Los grupos se han compuesto por un número medio de 6 personas.

En cuanto a los desplazamientos fuera de la comunidad de residencia para asistir a otros rallies, se observa que el $83 \%$ ha respondido que sí se desplazaba a otras comunidades con el fin de acudir a este tipo de eventos. Se observa, además, que todos se desplazaban principalmente a comunidades limítrofes con la suya, siendo para los gallegos los lugares más habituales: Asturias, Portugal, Castilla-León, Cantabria, Cataluña y Madrid (ver figura 2).

Figura 2. Ubicaciones más visitadas por los gallegos para asistir a rallies

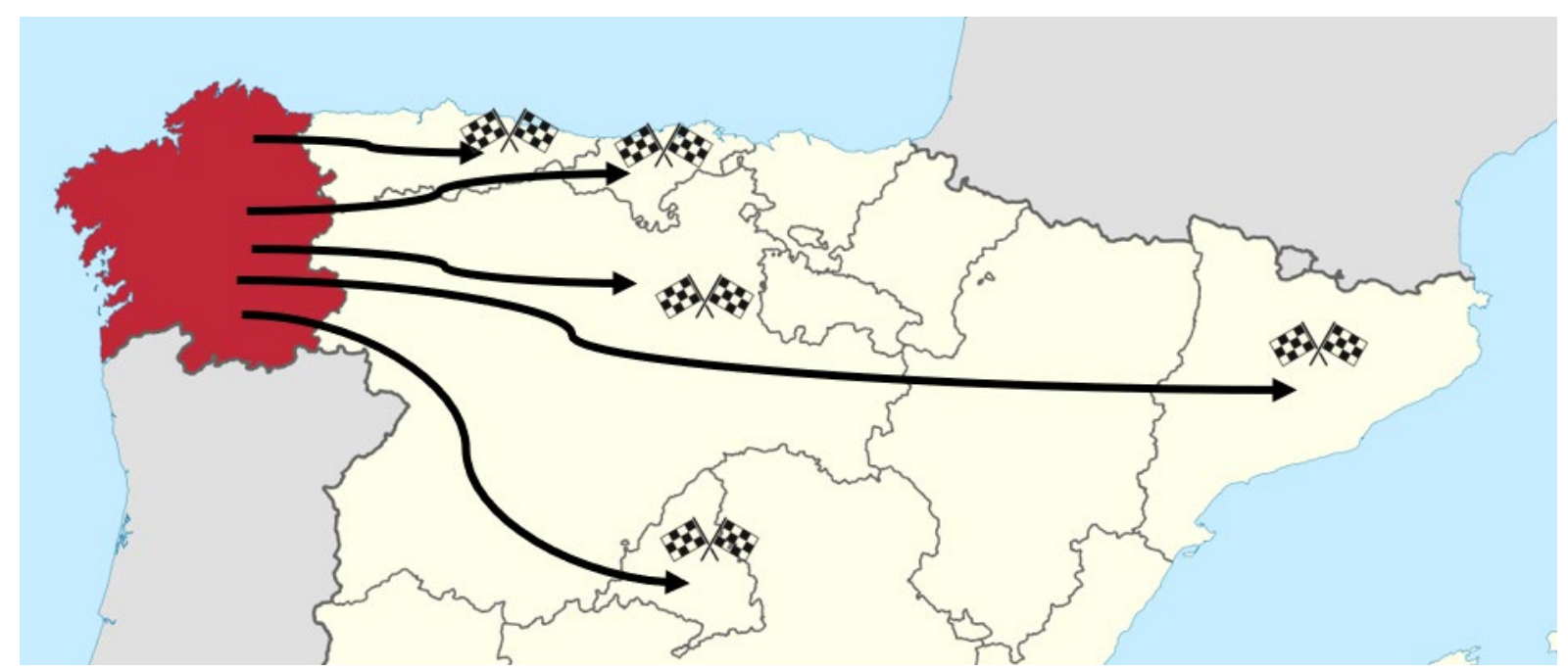

Existe entre los gallegos un porcentaje considerable (8,8\%) de personas que viajaban al destino para asistir a otras pruebas de automovilismo, principalmente a aquellas pertenecientes al WRC. Asimismo, el 70\% han asegurado que frecuentaban otro tipo de pruebas diferentes a los rallies de asfalto, asistiendo de media a 2 disciplinas por carrera, siendo las más frecuentes montañas, slalom, subida y autocross (Figuras 3-7). 
Figuras 3-7. Datos del perfil de asistente a rally

Compañía

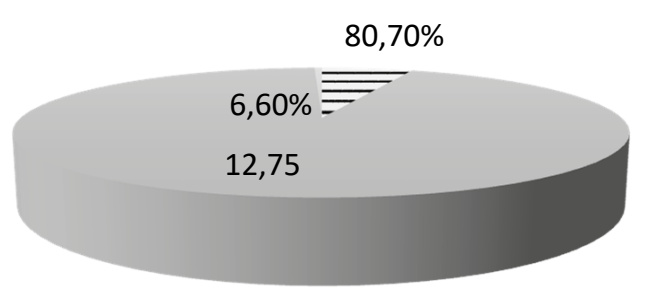

= En grupo Con mi pareja Solo

Lugares visitados

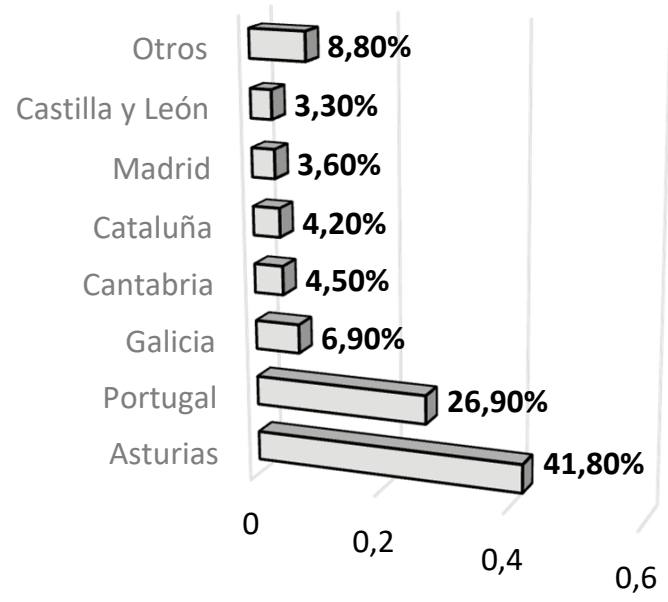

Viaja para asistir a eventos

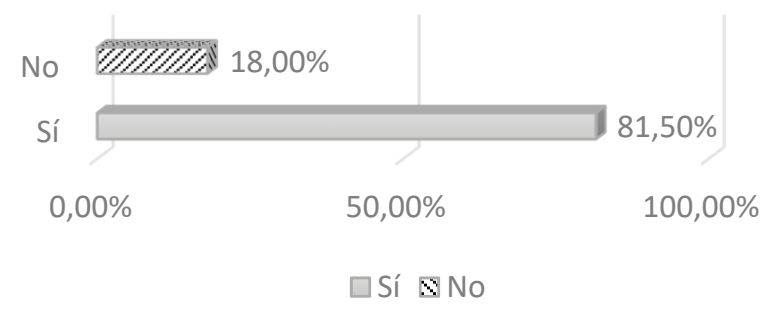

Asiste a otro tipo de eventos de motor

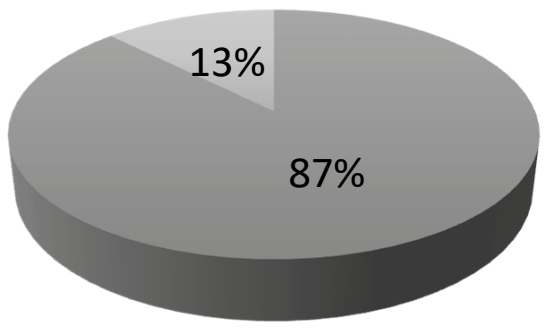

- Sí $\square$ No

Otros eventos a los que ha asistido

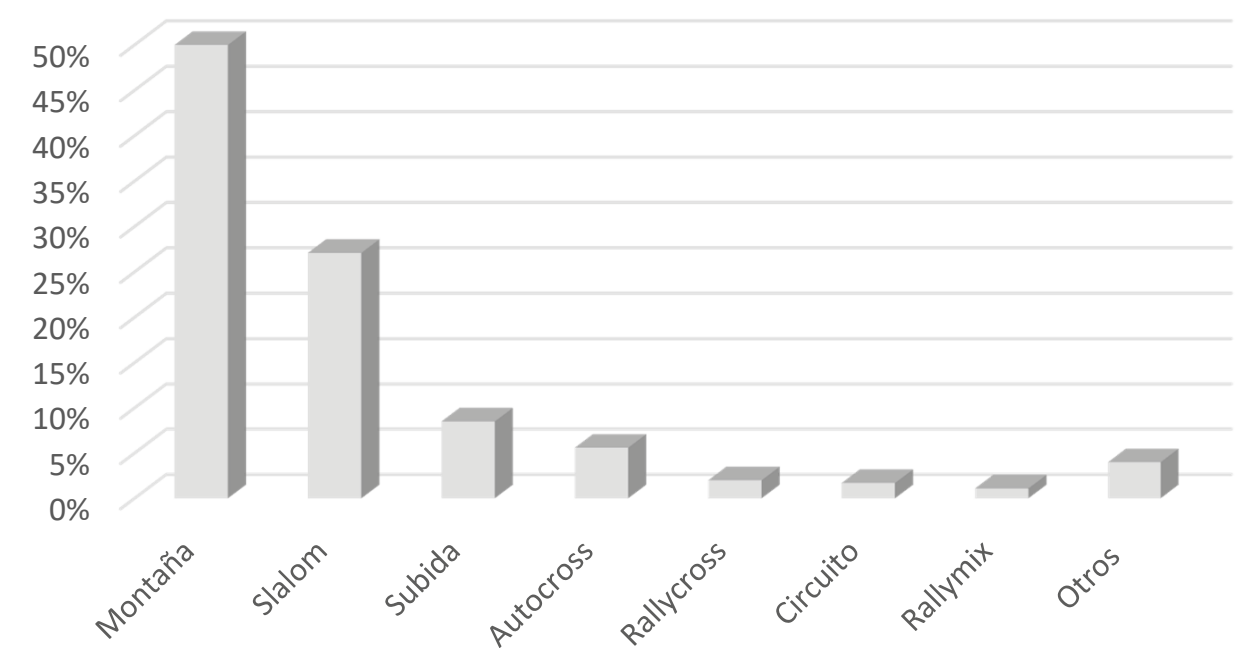




\subsection{Gasto turístico}

El tipo de alojamiento más utilizado por los asistentes a rallies ha sido el hotelero, seguido de la residencia habitual, casa de amigos o familiares, vehículo propio (coche, autocaravana o furgoneta) o tienda de campaña y otros alojamientos extrahoteleros (turismo rural, apartamentos turísticos...). Se hace uso del coeficiente de correlación de Pearson para comprobar si existe alguna correlación entre el género, edad, nivel educativo y ocupación y el tipo de alojamiento, pero ningún valor es próximo a 1, desestimando cualquier correlación (cuanto más próximo a 1 el valor obtenido más clara es la correlación). El mismo procedimiento se ha realizado con el gasto medio diario (estando el gasto medio diario promedio entre 26 y 50 euros), dándose la correlación más alta con la edad (coeficiente $=0,159$ y significativo). En concreto el valor medio más alto ha sido de más de 20 euros para los menores de 18 años y los del intervalo de 45 a 65 años. El segmento intermedio, de 19 a 44 años, ha gastado un valor medio de 16 a 20 euros por día en alojamiento (Figura 8). Aquí se analiza el gasto en alojamiento, pero en la tabla 7 se puede ver el gasto en actividades complementarias. Así el gasto medio diario total (alojamiento más actividades complementarias) se ha situado entre los 46 y 70 euros. En relación a la estancia media para esas pernoctas, la respuesta mayoritaria se ha situado entre 1 y 2 días en el $90 \%$ de los casos, habiéndose registrado solamente un caso que ha reconocido hospedarse fuera de su domicilio habitual más de 5 días.

Figura 8. Diagrama de cajas gasto medio diario en alojamiento/edad

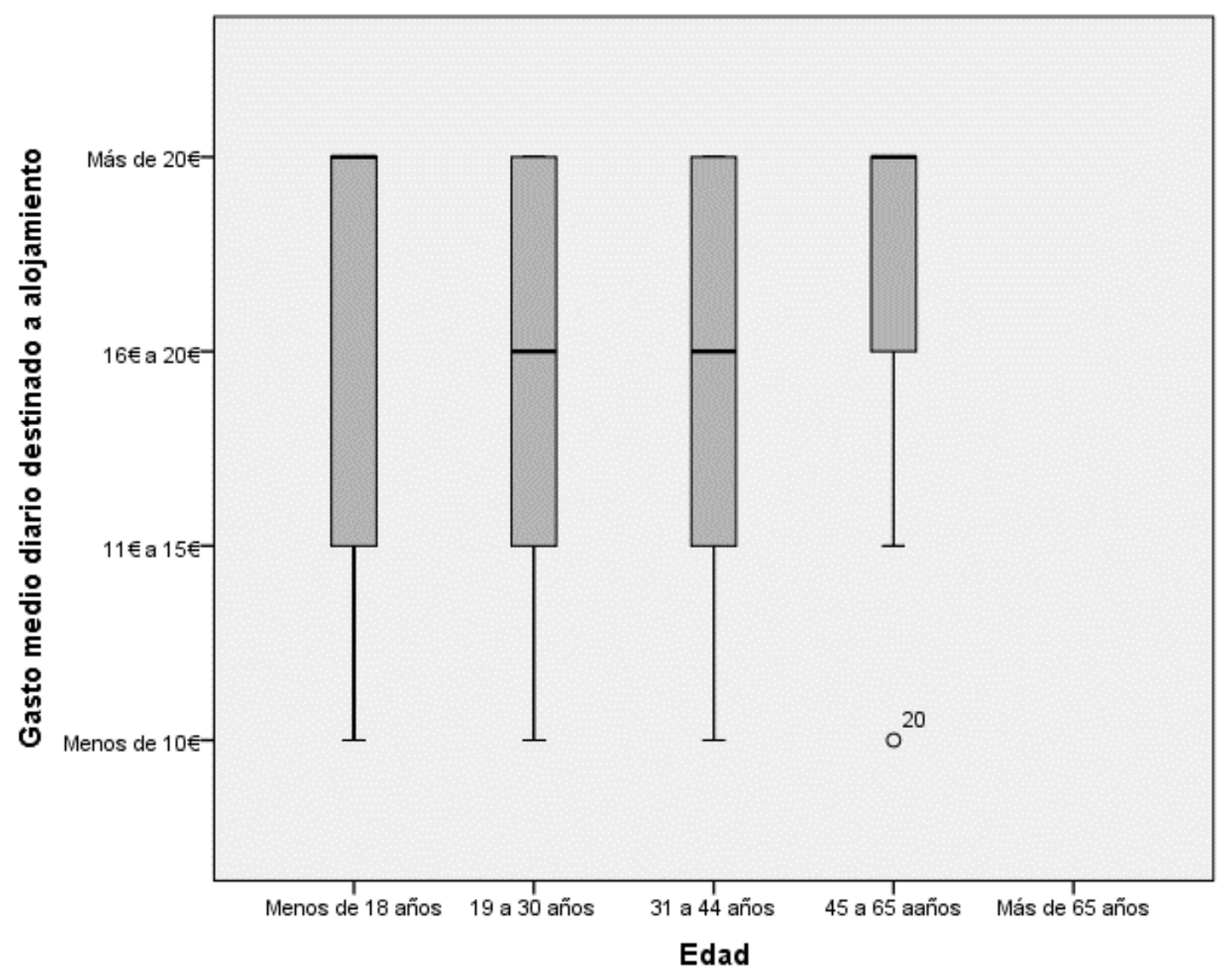


Tabla 5. Gasto turístico

\begin{tabular}{|c|c|c|}
\hline & $\mathbf{N}$ & $\%$ \\
\hline $\begin{array}{r}\text { Se hospeda fuera de su residencia habitual } \\
\text { para asistir a rallies }\end{array}$ & $N=504$ & \\
\hline Siempre & 7,3 & $33,5 \%$ \\
\hline Casi siempre & 10,9 & $25,8 \%$ \\
\hline A veces & 33,5 & $22,4 \%$ \\
\hline Casi nunca & 25,8 & $10,9 \%$ \\
\hline Nunca & 22,4 & $7,3 \%$ \\
\hline Tipo de alojamiento & $\mathbf{N}=504$ & \\
\hline Hotel/Bnb & 285 & $56,5 \%$ \\
\hline Residencia propia & 100 & $19,8 \%$ \\
\hline Turismo rural & 49 & $9,7 \%$ \\
\hline Otros & 38 & $7,5 \%$ \\
\hline Casa de amigos o familiares & 32 & $6,3 \%$ \\
\hline Duración de la estancia & \multicolumn{2}{|c|}{$\begin{array}{c}\mathrm{N}=406 \text { (no todos los encuestados } \\
\text { respondieron) }\end{array}$} \\
\hline Media & 1,10 & \\
\hline Moda & 1 & \\
\hline Desviación típica & ,313 & \\
\hline Mínimo & 1 & \\
\hline Máximo & 3 & \\
\hline Gasto media diario destinado a alojamiento & \multicolumn{2}{|c|}{$\begin{array}{c}\mathrm{N}=424 \text { (no todos los encuestados } \\
\text { respondieron) }\end{array}$} \\
\hline Menos de $25 €$ & 76 & $17,9 \%$ \\
\hline Entre $26 €$ y $50 €$ & 292 & $68,9 \%$ \\
\hline Más de $50 €$ & 56 & $13,2 \%$ \\
\hline $\begin{array}{r}\text { Hace uso de servicios complementarios como } \\
\text { restaurantes }\end{array}$ & $N=504$ & \\
\hline Sí & 464 & $92,1 \%$ \\
\hline No & 40 & $7,9 \%$ \\
\hline Gasto medio en servicios complementarios & $N=504$ & \\
\hline Hasta $10 €$ & 41 & $8.1 \%$ \\
\hline De $11 €$ a $15 €$ & 128 & $25.4 \%$ \\
\hline De $16 €$ a $20 €$ & 158 & $31.3 \%$ \\
\hline Más de $20 €$ & 177 & $35.1 \%$ \\
\hline
\end{tabular}




\subsection{Actividades turísticas realizadas y potencial de consumo turístico futuro}

El 44,6\% de la muestra ha reconocido realizar alguna actividad diferente a la deportiva, con una frecuencia de "algunas veces", seguida de los que afirman hacerlo casi nunca $(31,3 \%)$ (Tabla 6).

Los productos turísticos más consumidos han sido la gastronomía y el turismo cultural. De las respuestas facilitadas, se pudo conocer que, o bien sus intereses no eran muy variados, o no disponían de demasiado tiempo para practicar turismo, ya que solamente han consumido una media de 2 productos turísticos diferentes. Se ha considerado oportuno profundizar en aquellos casos en los que se admitiese no realizar ninguna actividad turística, para conocer si suelen volver en otro momento para visitar la zona. El 22,5\% han respondido que "casi nunca" o "nunca".

Tabla 6. Participación en actividades turísticas mientras viaja para asistir a eventos de rally

\begin{tabular}{rrr}
\hline & $\mathbf{N}=\mathbf{5 0 4}$ & $\mathbf{\%}$ \\
\hline Participación en actividades turísticas cuando acude a pruebas & & \\
automovilísticas & & \\
Siempre & 15 & $3,0 \%$ \\
Casi Siempre & 58 & $11,5 \%$ \\
Algunas veces & 225 & $44,6 \%$ \\
Casi nunca & 158 & $31,3 \%$ \\
Nunca & 48 & $9,5 \%$
\end{tabular}

Actividades turísticas más populares

Turismo gastronómico $316 \quad 62,7 \%$

Turismo cultural $177 \quad 35,1 \%$

Turismo activo o de aventura $123 \quad 24,4 \%$

Turismo de compras $103 \quad 20,4 \%$

No realiza ningún tipo de actividad turística $67 \quad$ 13,3\%

Turismo termal $57 \quad 11,3 \%$

Otros $82 \quad 16,3 \%$

Revisita a la zona (en caso de no haber realizado actividades turísticas durante la jornada de la prueba automovilística)

$\begin{array}{rcc}\text { Siempre } & 14 & 2,8 \% \\ \text { Casi siempre } & 85 & 16,9 \% \\ \text { Algunas veces } & 292 & 57,9 \% \\ \text { Casi nunca } & 84 & 16,7 \% \\ \text { Nunca } & 29 & 5,8 \%\end{array}$


Ha practicado previamente alguna actividad turística en alguna otra ocasión que asistiese a un rally

$\begin{array}{rrr}\text { Sí } & 329 & 69,3 \\ \text { No } & 146 & 30,7\end{array}$

Tipo de actividades turísticas practicadas en viajes previos a pruebas automovilísticas

$\begin{array}{rcc}\text { Turismo gastronómico } & 241 & 47,8 \% \\ \text { Turismo cultural } & 217 & 43,1 \% \\ \text { Turismo activo o de aventura } & 114 & 22,6 \% \\ \text { Turismo de compras } & 83 & 16,5 \% \\ \text { Turismo de sol y playa } & 3 & 0,6 \% \\ \text { Turismo termal } & 2 & 0,4 \%\end{array}$

Además, el $41,1 \%$ de ellos afirman que estarían dispuestos o muy dispuestos a comprar un paquete en el que se incluyesen alojamiento y actividades complementarias (Tabla 7). La respuesta mayoritaria se ha situado en 3 (en una escala del 1 al 5) y han reconocido estar dispuestos a pagar por él una media de $96 €$.

Con el fin de profundizar todavía más en los intereses de estos individuos, se les preguntó qué les motivaría para ampliar su estancia en la localidad donde tienen lugar las pruebas. La mayoría coincidieron en que sería necesaria "una mayor oferta cultural", seguida de mayor oferta turística, entorno o eventos relacionados con el mundo del motor.

Tabla 7. Potencial de consumo turístico futuro

\begin{tabular}{|c|c|c|}
\hline & $\mathbf{N}$ & $\%$ \\
\hline $\begin{array}{r}\text { Disponibilidad para comprar un paquete que incluye alojamiento y } \\
\text { actividades turísticas }\end{array}$ & \multicolumn{2}{|c|}{$N=504$} \\
\hline Totalmente dispuesto & 74 & $14,7 \%$ \\
\hline Muy dispuesto & 133 & $26,4 \%$ \\
\hline De alguna manera dispuesto & 173 & $34,3 \%$ \\
\hline Un poco dispuesto & 65 & $12,9 \%$ \\
\hline Nada dispuesto & 59 & $11,7 \%$ \\
\hline Disponibilidad de pago del paquete & \multicolumn{2}{|c|}{$\begin{array}{c}\mathrm{N}=418 \text { (no todos } \\
\text { los encuestados } \\
\text { respondieron) }\end{array}$} \\
\hline Hasta $20 €$ & 56 & 13,4 \\
\hline De $21 €$ a $50 €$ & 123 & 29,4 \\
\hline De $51 €$ a $75 €$ & 37 & 8,9 \\
\hline De $76 €$ a $100 €$ & 101 & 24,2 \\
\hline De $101 €$ a $150 €$ & 46 & 11,0 \\
\hline
\end{tabular}


De $151 €$ a $200 €$

Más de $200 €$

\begin{tabular}{|c|c|c|}
\hline \multirow[b]{2}{*}{ Oferta cultural (eventos, fiestas, ferias) } & \multicolumn{2}{|c|}{$\begin{array}{c}\mathrm{N}=244 \text { (no todos } \\
\text { los encuestados } \\
\text { respondieron) }\end{array}$} \\
\hline & 66 & $27,0 \%$ \\
\hline Mayor oferta turística (actividades turísticas, visitas guiadas) & 49 & $20,1 \%$ \\
\hline Entorno (cuidado del entorno, paisaje, naturaleza) & 45 & $18,4 \%$ \\
\hline Actividades relacionadas con el mundo del motor & 39 & $16,0 \%$ \\
\hline Disponer de más tiempo libre & 22 & $9,0 \%$ \\
\hline Precio & 13 & $5,3 \%$ \\
\hline Oferta gastronómica & 10 & $4,1 \%$ \\
\hline
\end{tabular}

Más del $40 \%$ de la muestra mostró estar muy interesado, interesado o totalmente interesado en comprar un paquete que incluyese alojamiento y actividades turísticas. Entre ellos, el tipo de actividad que despiertan más interés es el turismo gastronómico, seguido del turismo de aventura. Además, a excepción del turismo cultural, todos los tipos de turismo muestran medias superiores a 3, es decir, más próximas a 4 (sí están interesados).

Tabla 8. Interés en las actividades turísticas por tipo

\begin{tabular}{llcc}
\hline & N* & Media & Desv. típica \\
\hline Turismo gastronómico & 426 & 3,68 & 1,073 \\
Turismo activo o de aventura & 406 & 3,60 & 1,025 \\
Turismo de sol y playa & 396 & 3,31 & 1,225 \\
Festivales de música & 394 & 3,19 & 1,243 \\
Turismo termal & 387 & 3,10 & 1,238 \\
Turismo cultural & 377 & 2,97 & 1,096 \\
\hline \multicolumn{2}{c}{ Escala 1 = “No me interesa nada” y 5 = "Totalmente interesado” } \\
*Se indica el número de encuestados que valoró cada ítem \\
\hline
\end{tabular}

Finalmente, se ha realizado un análisis clúster de la muestra (conglomerado de $\mathrm{k}$ medias) para analizar posibles grupos con comportamientos homogéneos dentro los asistentes a rallies. Así, encontramos tres grupos diferenciados:

- Clúster 1: denominado senior en activo con interés en el turismo gastronómico y activo. Se trata de un grupo masculino, de edad entre 45 y 65 años, educación secundaria y laboralmente activo. Lo que les motiva al asistir a los rallies es acompañar a amigos y familiares, con un gasto medio en alojamiento de 16-20 euros. El tipo de turismo que realizan paralelo a su estancia es el gastronómico y activo.

- Clúster 2: denominado femenino joven interesado en el rally. En este grupo predominan las mujeres de entre 19 y 30 años con estudios de formación profesional y actualmente 
en una situación laboral no activa. Acuden a los rallies porque les gusta (son fans), pero no participan en la carrera. El gasto medio diario es de entre 16 y 20 euros, se alojan en un hotel y no muestran interés por los tipos de turismo propuestos en el estudio. Su objetivo es disfrutar del rally.

- Clúster 3: fans de los rally interesados en turismo complementario. Este tercer grupo está formado principalmente por hombres jóvenes (19-30 años), con el nivel más alto de estudios (postgrado), trabajadores (ya sea por cuenta propia o autónomos) y que acuden al rally porque les gusta (son fans). No son participantes de la carrera y realizan el gasto diario medio en alojamiento más bajo, menos de 10 euros, no alojándose en los establecimientos convencionales. Este grupo sí que muestra interés en complementar el rally con turismo en la zona, principalmente cultural, gastronómico y activo.

Del análisis clúster realizado, se concluye que del total de asistentes se establecen diferencias significativas entre los que acuden motivados por el propio rally y los que acompañan a amigos y familiares, así como los que solo muestran interés en el rally y los que desean combinar la experiencia con turismo.

\section{DISCUSIÓN}

En lo que respecta al marco teórico del trabajo, de la revisión literaria realizada se revela, en primer lugar, una problemática en cuanto a la contextualización del término turismo deportivo. Las definiciones que se encuentran, generalmente, no arrojan gran cantidad de información y tampoco existe un consenso en cuanto a la forma de practicar turismo deportivo; por lo tanto, no se puede extraer una clasificación unánime (Weed, 2009).

Resulta paradójico que a pesar de que autores relevantes en esta materia como Getz (2003) reconozcan la importancia de este tipo de eventos para las comunidades locales en términos de dinamización turística e impacto económico, los estudios de caso sean limitados y se reduzcan solo a grandes eventos deportivos. Cada vez más son los autores que analizan el impacto económico en el sector deportivo (Salgado-Barandela, Barajas y Sánchez-Fernández, 2017), pero todavía no son numerosos en este sector. Green y Chalip (1998) hacían alusión a este hecho, pero a nivel académico todavía no se han hecho avances al respecto.

Los estudios que se hallan se limitan al impacto económico. Si bien estos estudios revelan la importancia de estos eventos en términos monetarios para un destino, apenas existen investigaciones que se centren en analizar en profundidad a este tipo de turista. Como se acaba de avanzar, se barajan datos sobre número de espectadores, datos realmente elevados. Si a esto se le suma la fidelidad de este tipo de turista (superior a la media), los motivos expuestos convierten a este deporte en un caso de especial interés con respecto a los demás. Por lo tanto, se reitera la existencia de un problema, ya que, sin un conocimiento ampliado sobre el comportamiento de este tipo de turista, difícilmente se pueden crear acciones específicas dirigidas al mismo.

De ahí que este trabajo se centre en el perfil de este tipo de turista, objetivo del trabajo, buscando así profundizar en este aspecto hasta ahora menos investigado. Los primeros estudios se centraron en las propias definiciones del concepto (Hall, 1992; Secall, 1991; Standeven 
y Knop, 1999) o en establecer clasificaciones dentro del mismo (Gibson, 1998; Kurtzman y Zauhar, 1997; Standeven y Knop, 1999). De ahí se pasó a los propios eventos deportivos y el turismo derivado de estos, estableciéndose definiciones de lo qué englobaba esta práctica. Hoy en día siguen vigentes las ya adelantadas por Delpy Neirotti (2003) donde el evento deportivo se convierte en atracción turística. Es en la década del 2000 y 2010 cuando el interés se centra en el comportamiento turístico, pero sin establecerse un perfil claro. Lo que sí queda demostrado es el impacto e interés que generan este tipo de eventos, por lo que en términos de investigación de mercado se hace extraño no encontrar más estudios sobre el perfil de un turista de un nicho de mercado creciente y con cierta repercusión económica en un destino.

Por ello el presente trabajo busca suplir dichas carencias planteando aspectos concretos de este perfil de turista. En primer lugar, un perfil que nos permita hacernos una idea de los rasgos de este colectivo, verificando así aspectos como el género (hasta ahora en mayor cantidad masculino que femenino en este tipo de eventos) y otras variables como la edad $u$ ocupación. También, haciendo así alusión a los estudios que analizan el impacto económico, el gasto realizado, desagregando el alojamiento de otros servicios complementarios. Y finalmente las actividades turísticas realizadas, verificando si el interés se centra exclusivamente en el evento deportivo o éste funciona como atrayente del destino y a su vez se consume turismo en el destino.

\section{CONCLUSIONES}

De los resultados obtenidos durante la investigación empírica de este trabajo, y dando así respuesta al objetivo planteado (perfil y comportamiento del asistente a rallies de asfalto) se concluye que la mayoría de la población de estudio tiene un alto grado de fidelidad en cuanto a la asistencia a las pruebas automovilísticas, dado que los individuos en cuestión acuden a un gran número de pruebas en el ámbito gallego (entre 4-7 del CGR y 2 del CERA). Se trata de una actividad que atrae en su mayor parte al género masculino y de edad joven (entre 19 y 30 años). Además, se desplazan a zonas próximas a su lugar de residencia, bien en la propia comunidad o comunidades limítrofes (objetivo específico 1). Manifiestan mayoritariamente hospedarse fuera de su residencia habitual, pero limitándose su estancia a los días de la prueba solamente. Aun así, realizan un gasto medio diario por individuo de entre 46 y 70 euros, incluyéndose el alojamiento y otras actividades complementarias, entre ellas la restauración (objetivo específico 2). A esto se suma que solo algunas veces vuelven para conocer mejor el destino (57,9\%), encontrándose aquí una de las primeras debilidades para el sector turístico, ya que el comportamiento de estos individuos es totalmente diferente cuando acuden a pruebas fuera de su comunidad o país. En este último caso, el 70\% reconoce que sí realiza actividades turísticas, mientras que dentro de la comunidad este porcentaje se reduce al 3\% (para la respuesta siempre). El porqué de este hecho es puesto de manifiesto por parte de dichos individuos alegando que existe una falta de oferta cultural y turística (objetivo específico 3).

En Galicia no existe una oferta especializada para este nicho de mercado, los destinos no son capaces de retenerlos durante más tiempo al de la duración de la prueba, acto que se 
agrava al no realizarse una correcta difusión de la información sobre los recursos turísticos cercanos a los lugares de desarrollo de las carreras.

Por todo lo expuesto anteriormente, y dada la contrastada relevancia de este deporte en la comunidad gallega, puede tomarse este estudio como precedente para la continuación de la investigación en relación a esta temática, así como aliciente para la creación de propuestas turísticas adaptadas realmente a esta tipología de turista. Información valiosa para ello son los clústers encontrados en este estudio, diferenciando entre los que muestran interés en practicar turismo y a los que solo les interesa el rally. Este último hallazgo es relevante, ya que se muestra que existen asistentes a rallies interesados en la práctica turística en el destino. $A$ priori este es el grupo que más interés suscita a un destino, pudiendo incentivar el prolongar su estancia más allá de la duración del evento turístico si se le ofrece una interesante oferta turística complementaria. Por ello, como implicaciones prácticas, se propone a los propios destinos la necesidad de difundir información de interés turístico a los asistentes a rallies. Tal vez llegar a acuerdos de cooperación con los propios eventos y difundiendo esta información a través de las webs y redes sociales de los eventos deportivos. También, se recomienda que recopilen datos sobre los asistentes a este tipo de eventos. La información obtenida será valiosa para organizar productos y paquetes turísticos adecuados a la demanda, principalmente a este grupo detectado. De ahí la necesidad de llevar a cabo observatorios turísticos durante la realización de estos eventos o diseñar encuestas que se pueden recoger en las propias oficinas de turismo o durante los eventos. El conocer el perfil del turista de un destino y sus motivaciones y aspiraciones turísticas es clave para adaptar la oferta a la demanda. Además, se pueden plantear preguntas de valoración del destino, pudiendo con dicha información mejorar sus puntos débiles. Por otro lado, se anima a los destinos a organizar eventos deportivos en general, ya que atraen a un gran número de participantes y espectadores, pudiendo dinamizar el turismo y economía del destino. En la sociedad actual la preocupación por la salud y la práctica deportiva es una realidad, siendo el deporte ya una motivación notable para la elección de la visita a un destino.

Por último, comentar como limitaciones del trabajo, que la muestra analizada se centra en los rallies de asfalto disputados en Galicia. En futuras investigaciones los autores de esta investigación recogerán muestras de otros tipos de eventos deportivos automovilísticos y en otros territorios, ampliando de esta forma la muestra y pudiendo incluso realizar comparativas entre los perfiles de los diferentes eventos.

\section{REFERENCIAS BIBLIOGRÁFICAS}

ACP. (2016). Estudo do Impacto do WRC Vodafone Rally de Portugal na Economia do Turismo e Formação da Imagen dos Destinos: Região Norte de Portugal.

Armstrong, J. (1986). International events and popular myths. In International events: the real tourism impact. Proceedings of the Canada Chapter Travel and Tourism Association annual conference, Westin Hotel, Edmonton, Alberta, October 20-22, 1985. (pp. 9-37).

Baker, M. J., y Gordon, A. W. (1976). The Market for Winter Sports Facilities in Scotland. Research and Planning Division, Scottish Tourist Board. 
Barajas, Á., Salgado, J., y Sánchez, P. (2012). Problemática de los estudios de impacto económico de eventos deportivos. Estudios de economía aplicada, 30(2), 441-461.

Beioley, S., Crookston, M., y Tyrer, B. (1988). London docklands: the leisure element. Leisure Management, 8(2), 30-33.

Burgan, B., y Mules, T. (1992). Economic impact of sporting events. Annals of tourism research, 19(4), 700-710.

Chalip, L. (2004). Beyond impact: A general model for sport event leverage. In Ritchie, B. y Adair, D. (edit.). Sport tourism: Interrelationships, impacts and issues. Clevedon: Channel View Publications.

Chalip, L., Green, B. C., y Hill, B. (2003). Effects of sport event media on destination image and intention to visit. Journal of sport management, 17(3), 214-234.

Comisión Europea. (2006). Una nueva política turística en la UE: hacia una mayor colaboración en el turismo europeo. Bruselas: COM (2006), 134 final.

Daniels, M. J., Norman, W. C., y Henry, M. S. (2004). Estimating income effects of a sport tourism event. Annals of tourism research, 31(1), 180-199.

Del Chiappa, G., Tinaz, C., y Turco, D. M. (2014). Driving first-time and repeat spectators to a motor sport event. International Journal of Culture, Tourism and Hospitality Research, 8(4), 388-400.

Delpy Neirotti, L. (2003). An introduction to Sport an Adventure Tourism. En S. Hudson, Sport and Adventure Tourism (pp. 1-26). Binghamtom: The Haworth Hospitality Press.

Deporte Galego (2019). Deportistas Galegos de Alto Nivel (DGAN). Recuperado el 23 de junio de 2019, de Xunta de Galicia: https://deporte.xunta.gal/gl/deportistas/ deportistas-galegos-de-alto-nivel-dgan

FGA (17 de septiembre de 2013). Estatutos e Regulamento de Réxime Disciplinario da Federación Galega de Automobilismo. Recuperado el 22 de junio de 2019, de Federación Galega de Automobilismo.

FGA (2019a). Calendario FGA 2019. Recuperado el 10 de junio de 2019, de Federación Galega de Automobilismo.

FGA (2019b). Dossier Presentación "Campionato de Rallyes" 2019. Recuperado el 20 de febrero de 2019, de Federación Galega de Automobilismo.

FIA(2018).ActivityReport2018. Recuperadoel12 dejuniode2019, deFederación Internacionalde Automovilismo: https://www.fia.com/multimedia/publication/2018-fiaactivity-report

FIA (2019). International Sporting Calendar. Season 2019. Recuperado el 12 de junio de 2019, de Federación Internacional de Automovilismo.

Gammon, S., y Robinson, T. (1997). Sport and tourism: A conceptual framework. Journal of Sport Tourism, 4(3), 11-18.

Getz, D. (2003). Sport event tourism: planning, development and marketing. En Hudson (Ed.). Sport and Adventure Tourism. New York: The Haworth Hospitality Press, pp.49-88.

Getz, D. (2008). Event tourism: Definition, evolution, and research. Tourism Management, 29, 403-428.

Getz, D., y McConnell, A. (2011). Serious sport tourism and event travel careers. Journal of Sport Management, 25(4), 326-338.

Gibson, H. J. (1998). Sport tourism: a critical analysis of research. Sport management review, 1(1), 45-76. 
Gibson, H. (2005). Sport tourism: Concepts and theories. An introduction. Sport in Society, 8(2), 133-141.

Gibson, H. J., Qi, C. X., y Zhang, J. J. (2008). Destination image and intent to visit China and the 2008 Beijing Olympic Games. Journal of Sport Management, 22(4), 427-450.

Gibson, H. J., Willming, C., y Holdnak, A. (2003). Small-scale event sport tourism: Fans as tourists. Tourism management, 24(2), 181-190.

Glyptis, S. (1982). Sport and tourism in Western Europe. London: British Travel Educational Trust.

González Molina, A. (2008). Rasgos caraterizadores del turismo activo y turismo deportivo e importancia económico-social y estructural de nuevas formas emergentes. Acciónmotriz.

Gratton, C., Dobson, N., y Shibli, S. (2000). The economic importance of major sports events: a case-study of six events. Managing leisure, 5(1), 17-28.

Green, B. C., y Chalip, L. (1998). Sport tourism as the celebration of subculture. Annals of Tourism Research, 25(2), 275-291.

Hall, C. M. (1992). Adventure, sport and health tourism. London: Belhaven Press, pp.141-158.

Hassan, D., y McCulloch, D. (2007). An Economic Impact Study of Round 15 of the World Rally Championship 2007: Rally Ireland.

Hassan, D., y Connor, S. O. (2009). The socio-economic impact of the FIA World Rally Championship 2007. Sport in Society, 12(6), 709-724.

Henry, N., Angus, T., Jenkins, M., y Aylett, C. (2007). Motorsport Going Global. In Motorsport Going Global (pp. 132-156). Palgrave Macmillan: London.

Higham, J. (2018). Sport tourism development. Channel view publications.

Hinch, T. e Ito, E. (2018). Sustainable sport tourism in Japan. Tourism Planning \& Development, 15(1), 96-101.

Instituto Nacional de Estadística (2019). Encuesta de turismo de residentes. Recuperado el 20 de febrero de 2019, de: https://www.ine.es/

Jiménez Naranjo, H. V. (2015). Análisis del impacto socioeconómico de los eventos deportivos. (Tesis doctoral), Universidad de Extremadura.

Kaplanidou, K., y Vogt, C. (2007). The interrelationship between sport event and destination image and sport tourists' behaviours. Journal of Sport \& Tourism, 12(3-4), 183-206.

Kiani, M. S., Nazari, L. y Shahbazpour, L. (2019). Sport Tourism and Sustainable Local Development for Host Cities for Sporting Events. American Journal of Sports Science, 7(1), 7-10.

Kolsun, J. (1988). The Calgary Winter Olympics visitor study. The Operational Geographer, 16, 15-17.

Kurtzman, J., y Zauhar, J. (2003). A wave in time-The sports tourism phenomena. Journal of Sport Tourism, 8(1), 35-47.

Latiesa, M., y Paniza, J. L. (2006). Turistas deportivos. Una perspectiva de análisis. Revista internacional de sociología, 64(44), 133-149.

Lazer, T. A. M. M. Y. (1986). The 1985 Los Angeles Olympics. In International events: the real tourism impact. Proceedings of the Canada Chapter Travel and Tourism Association annual conference, Westin Hotel, Edmonton, Alberta, October 20-22, 1985. (pp. 137-140). 
Livesey, H. (1990). Barcelona: rising to new heights. Travel and Leisure, 6, 136-160.

McDowell, D., Leslie, D., y Callicot, R. (1988). The Birmingham Olympic bid: selling a city. In Proceedings of the 1st international conference, planning for tourism and leisure. University of Ulster at Jordanstown Newton Abbey: NI.

Mackellar, J. (2013). World Rally Championship 2009: Assessing the community impacts on a rural town in Australia. Sport in Society, 16(9), 1149-1163.

Mackellar, J., y Reis, A. C. (2014). World Rally Championships 2009 and 2011: Assessing the tourism value in Australia. Journal of Vacation Marketing, 20(1), 17-28.

Malhotra, N. K. (2004). Investigación de mercados: un enfoque aplicado. Pearson educación.

MECD (2019). Anuario de Estadísticas Deportivas. Ministerio de Cultura y Deporte, División de Estadística y Estudios, Secretaría General Técnica.

Mejía, A. (2009). Deporte: ¿Fenómeno natural y eterno o creación socio-histórica? ABI, 18(4).

Nyikana, S. y Tichaawa, T. (2018). Sport tourism as a local economic development enhancer for emerging destinations. EuroEconomica, 37(2).

O'Brien, D. (2007). Points of leverage: Maximizing host community benefit from a regional surfing festival. European Sport Management Quarterly, 7(2), 141-165.

O'Connor, S. (2010). Project Management and the Development of Social Capital at Rally Ireland 2007. Choregia, 6(1).

O'Connor, S. (2012). Sport event management. En L. Trenberth, \& D. Hassan, Managing Sport Bussiness. An introduction. Abignon: Routledge.

Paramio-Salcine, J. L., Barquín, R. R., y Arroyo, M. J. B. (2017). Identidad urbana y el turismo de eventos deportivos: el Grand Depart Tour de Francia 2015. Cuadernos de turismo, 40, 489-520.

Perić, M. (2018). Estimating the perceived socio-economic impacts of hosting large-scale sport tourism events. Social Sciences, 7(10), 176.

Perić, M., Vitezić, V. y Badurina, J. Đ. (2019). Business models for active outdoor sport event tourism experiences. Tourism Management Perspectives, 32, 100561.

Pigeassou, C. (2004). Contribution to the definition of sport tourism. Journal of Sport \& Tourism, 9(3), 287-289.

RACC (2009). Impacto Económico de 44 Rally RACC Catalunya-Costa Daurada. BCP Consulting Group y Universidad Rovira y Virgili.

Rasku, R., y Turco, D. M. (2017). The Personal Value Structures of Rally Spectators and Rally Team Members. In Creating Marketing Magic and Innovative Future Marketing Trends (pp. 1035-1048). Springer, Cham.

RFEDA. (2019). Real Federación Española de Automovilismo. https://www.rfeda.es/

Ritchie, J. R. (1984). Assessing the impact of hallmark events: Conceptual and research issues. Journal of travel research, 23(1), 2-11.

Ritchie, B. W., y Adair, D. (Eds.). (2004). Sport tourism: Interrelationships, impacts and issues (Vol. 14). Channel View Publications.

Salgado-Barandela, J., Barajas, A., y Sánchez-Fernández, P. (2017). Impacto económico del deporte: tema de interés creciente en la literatura científica. Revista Internacional de Medicina y Ciencias de la Actividad Física y del Deporte, 17 (68), 729-755.

Sánchez-Fernández, P., Barajas, Á., y Alén González, M. E. (2013). Los eventos deportivos como herramienta de promoción turística: propuestas para el Rally de Ourense y su entorno 
(Sport Events as a Tool for Tourism Promotion: Proposals for Rally Ourense and Its Enviroment). Revista de análisis turístico, 16, 59-69.

Secall, R. (1991). Análisis teórico de las relaciones entre el turismo y el deporte, referencia especial a Andalucía. I Jornadas sobre Turismo y Deporte, Consejería de Cultura, Instituto Andaluz del Deporte.

Standeven, J., y Knop, P. (1999). Sport Tourism, Human Kinetics. USA: USA Human Kinetics:

Torralba Cano, J. (2015). Análisis del impacto económico del 45 Rally de Ferrol en la comarca de Ferrol terra.

Weed, M. (2009). Progress in sports tourism research? A meta-review and exploration of futures. Tourism Management, 30(5), 615-628.

Williams, A. V., y Zelinsky, W. (1970). On some patterns in international tourist flows. Economic Geography, 46(4), 549-567.

WRC (2019a). World Rally Championship. Recuperado el 10 de junio de 2019, de: https://www. wrc.com/en/

WRC (2019b). WRC Factbook 2019. Recuperado el 10 de junio de 2019, de: https://www.wrc. com/factbook/2022/\#0

Yeh, C. C., Lin, C. S. y Huang, C. H. (2018). The total economic value of sport tourism in Belt and Road development-An environmental perspective. Sustainability, 10(4), 1191.

\section{CONTRIBUCIONES}

1) la concepción original del trabajo: Cristina Rico;

2) el análisis, adquisición e interpretación de los datos: Cristina Rico y Noelia Araújo,

3) la redacción y revisión crítica del contenido: Cristina Rico, Noelia Araújo y Jose A. Fraiz y;

4) la aprobación final de la versión a publicar: Cristina Rico, Noelia Araújo y Jose A. Fraiz. 